\title{
ARTICLE
}

\section{Mental capacity assessment and 'best interests' decision-making in clinical practice: a case illustration}

\author{
Asit B. Biswas \& Avinash Hiremath
}

\begin{abstract}
Asit B. Biswas is a consultant psychiatrist in learning disability with the Leicestershire Partnership NHS Trust and a Fellow of the Royal College of Psychiatrists. Avinash Hiremath is a locum consultant psychiatrist in learning disability with the Leicestershire Partnership NHS Trust. Correspondence Dr Asit Biswas, Leicester Frith Hospital, Groby Road, Leicester LE3 90F, UK.
\end{abstract} Email: asitbiswas@yahoo.co.uk

${ }^{t}$ For a discussion of the deprivation of liberty safeguards see Brindle \& Branton (pp. 430-437) and Lyons (pp. 438-439), this issue. Ed.

\begin{abstract}
SUMMARY
Mental capacity refers to a person's ability to make decisions, which may include consenting to medical treatment. People are presumed to have this capacity. Individuals may lack capacity because of an impairment or disturbance that affects the way their mind or brain works. Legal frameworks are in place for acting and making decisions on behalf of individuals who lack the mental capacity to do so for themselves, in their best interests. A case illustration is used to outline the principles involved under the Mental Capacity Act 2005 for England and Wales. We describe in detail the assessment of capacity to consent to treatment in this case and good practice in making best interests decisions in everyday clinical practice.
\end{abstract}

\section{DECLARATION OF INTEREST}

None.

Mental capacity can be defined as having 'sufficient understanding and memory to comprehend in a general way the situation in which one finds oneself and the nature, purpose, and consequence of any act or transaction into which one proposes to enter' (www.dictionary.com) - in other words, as the ability to make a decision. This includes the ability to make both day-to-day decisions and more serious or significant decisions. It also refers to a person's ability to make a decision that may have legal consequences for them or others, including agreeing to have medical treatment. The Mental Capacity Act 2005, which applies in England and Wales, provides the legal framework for acting and making decisions on behalf of individuals who lack the mental capacity to do so for themselves. The Adults with Incapacity (Scotland) Act 2000 applies in Scotland. In Northern Ireland, decisionmaking for patients lacking capacity is governed by common law.

The five statutory principles underpinning the Mental Capacity Act are given in Box 1. In essence, they state that: there should be a presumption of capacity unless it is proved otherwise; individuals should be supported to make their own decisions; that people have the right to make unwise decisions; the best interests of an incapacitous individual must be upheld; and the least restrictive option should always be pursued. The Act's deprivation of liberty safeguards ${ }^{\dagger}$ enhance the protection offered by these principles (Department of Health 2008). The patient has the right to accept or refuse treatment for a physical disorder for a reason that may seem irrational or for no reason at all. No one else can make a decision regarding treatment for a physical disorder on behalf of an adult who has capacity (Department of Health 2009: p. 19, para. 44).

According to the Mental Capacity Act, a person lacks capacity to consent to treatment if (i) they have impairment or disturbance that affects the way their mind or brain works and (ii) the impairment or disturbance means that they are unable to make a specific decision at the time it needs to be made. The law requires that treatment decisions for people lacking capacity must be made in their best interests.

BOX 1 The statutory principles underpinning the Mental Capacity Act 2005

- A person must be assumed to have capacity unless it is established that he lacks capacity

- A person is not to be treated as unable to make a decision unless all practicable steps to help him to do so have been taken without success

- A person is not to be treated as unable to make a decision merely because he makes an unwise decision

- An act done, or decision made, under this Act for or on behalf of a person who lacks capacity must be done, or made, in his best interests

- Before the act is done, or the decision is made, regard must be had to whether the purpose for which it is needed can be as effectively achieved in a way that is less restrictive of the person's rights and freedom of action

(Mental Capacity Act 2005: Part 1 (1)) 
In this article we use a case illustration to outline the principles and process involved in everyday clinical practice in the assessment of capacity to consent to treatment in accordance with the Mental Capacity Act Code of Practice (Department for Constitutional Affairs 2007). This includes using the expertise of a multidisciplinary team to comprehensively assess relevant aspects of the person's abilities in order to inform the capacity test, making a best interests decision with regard to serious medical treatment, the role of an independent mental capacity advocate and issues of confidentiality. The case of Ms A is published with permission of her family.

\section{Case report: summary details}

Ms A, aged 58 years, had mild intellectual disability ${ }^{\mathrm{a}}$ with behaviour disorder (ICD-10, F70.1) and unspecified non-organic psychosis (ICD-10, F29). She was born and brought up in England. Details of her birth and early development were not available. Ms A had a twin brother, who also had intellectual disability. Ms A was described as developing as a normal child until she reached 3 years of age, when she had tooth extractions under general anaesthesia. The family noted that she was not the same after the procedure. She became apathetic and uncommunicative. There were also reports of aggression. Her parents cared for her at home, seeking little input from local authority or health services, until Ms A was 36 years old, when her mother died. Her father could not cope with caring for her at home alone, particularly with her aggressive behaviour. Shortly thereafter, she was admitted to a general psychiatric in-patient unit for an assessment under Section 2 of the Mental Health Act 1983. Her records at the time note disruptive behaviour, unprovoked aggressive outbursts towards staff and other patients and persistent pica.

Ms A remained an in-patient for 6 years, after which time improvements in her behavioural problems secondary to pharmacological and behavioural treatment allowed her transfer to a nursing home. Unfortunately, 5 years later the nursing home closed and at the age of 47 Ms A was re-admitted to the hospital. Further assessment in hospital over a period of 2 years described episodes of aggression as if in response to auditory and visual hallucinations; impaired verbal communication and comprehension; and impairments in independent living skills. Cognitive assessments indicated that Ms A had an intellectual disability. She was transferred to the learning disability community services, at the age of 49 . Four years later she was admitted to a specialist learning disability in-patient unit because of aggressive behaviour attributed to relapse of psychotic illness. She improved with treatment with antipsychotic drugs and remained stable over a 2-year period, after which she was discharged to a residential care facility. She died at the age of 58 , of metastatic breast carcinoma.

\section{Assessment of capacity}

Ms A was diagnosed with carcinoma of the right breast at the age of 53, while she was a resident in the local specialist learning disability in-patient unit. A radical mastectomy was recommended by the surgical consultant. The Mental Capacity Act Code of Practice (Department for Constitutional Affairs 2007) states that, if a doctor or healthcare professional proposes treatment or an examination, they must assess the person's capacity to consent. In hospital settings, this can involve the multidisciplinary team, but ultimately it is up to the professional responsible for the person's treatment to make sure that capacity has been assessed.

Section 2(1) of the Mental Capacity Act states:

For the purpose of this Act, a person lacks capacity in relation to a matter if at the material time he is unable to make a decision for himself in relation to the matter because of impairment of, or a disturbance in the functioning of, the mind or brain.

An assessment of Ms A's capacity to consent to make an informed decision about surgical treatment and other treatment options was organised with guidance from the Mental Capacity Act Code of Practice (Box 2) with input from the multidisciplinary team involved in her care. The plan agreed was to optimise treatment of her psychotic symptoms and then assess her capacity to consent to surgery. The multidisciplinary team included a learning disability psychiatrist, a clinical psychologist, a community learning disability nurse, a speech and language therapist, a nurse from the outreach team, the named nurse from the in-patient unit, the manager of the patient's residential home, the specialist breast care nurse and the consultant surgeon.

A meeting with the multidisciplinary team was arranged to discuss the issues of capacity with Ms A and her family (two brothers, her sister and sister-in-law). During this meeting Ms A's capacity to make an informed decision would be formally assessed and, if she lacked capacity, a decision would be made in her best interests.

The information collected for this capacity assessment included the following:

- cognitive abilities

- adaptive and communication skills

- mental health a. The National Health Service in the UK refers to intellectual disability as learning disability. We have retained this terminology in discussing NHS units and staff. 


\section{BOX 2 Checklist of points to consider when assessing a person's capacity to make a specific decision}

1 Presuming someone has capacity The starting assumption must always be that a person has capacity to make a decision, unless it can be established that they lack capacity

2 Understanding what is meant by capacity and lack of capacity

3 Treating everyone equally

4 Supporting the person to make the decision for themselves

5 Assessing capacity

6 Assessing ability to make a decision

7 Assessing capacity to make more complex or serious decisions
A person's capacity must be assessed specifically in terms of their capacity to make a particular decision at the time it needs to be made

A person's capacity must not be judged simply on the basis of their age, appearance, condition or an aspect of their behaviour

It is important to take all possible steps to try to help people make a decision for themselves

Anyone assessing someone's capacity to make a decision for themselves should use the two-stage test of capacity:

stage 1: Does the person have an impairment of the mind or brain, or is there some sort of disturbance affecting the way their mind or brain works? (It does not matter whether the impairment or disturbance is temporary or permanent)

stage 2: If so, does that impairment or disturbance mean that the person is unable to make the decision in question at the time it needs to be made?

Does the person have a general understanding of what decision they need to make and why they need to make it? Does the person have a general understanding of the likely consequences of making, or not making, this decision? Is the person able to understand, retain, use and weigh up the information relevant to this decision?

Can the person communicate their decision (by talking, using sign language or any other means)? Would the services of a professional (such as a speech and language therapist) be helpful?

Is there a need for a more thorough assessment (perhaps by involving a doctor or other professional expert)?

(Department for Constitutional Affairs 2007)
- understanding of surgical/medical diagnosis and proposed treatment

- previous capacity to make complex decisions

- previous experience of medical investigations and treatment.

\section{Cognitive abilities}

In 1989, Ms A had been estimated to have an IQ of 70 using the Quick IQ test (Ammons 1962). A battery of cognitive assessments was arranged for the current capacity assessment, which included the Trail Making Test Part A (Reitan 1992), the Wechsler Memory Scale Revised Visual Memory Span subtest (Wechsler 1997a), Wechsler Adult Intelligence Scale III Picture Arrangement subtest (Wechsler 1997b) and Raven's Coloured Progressive Matrices (Raven 2003). The assessments indicated that Ms A had good attention and concentration, but these tended to deteriorate rapidly when she felt under pressure. Her shortterm working memory was noted to be impaired. Her ability to sequence, plan and organise a task was also limited, especially when the task had not been previously learned or rehearsed. Her verbal and non-verbal reasoning and problem-solving abilities were poor. These impairments appeared to be long-standing. Despite her previous IQ score of 70 , which places her on the borderline, her functioning was now assessed as equivalent to severe intellectual disability, probably owing to cognitive deterioration secondary to psychosis.

\section{Adaptive and communication skills}

A community healthcare assessment showed that Ms A had limited adaptive skills with regard to activities of daily living. With prompting and assistance, she could attend to her toilet needs, bathing, dressing, grooming and feeding. She enjoyed going out for walks but could not do so safely on her own as she had very little awareness of road safety. She could not shop for herself as she was unable to understand money and handle transactions. She seldom initiated conversations and responded in monosyllables when asked questions. It was difficult to explore Ms A's perceptions of herself, her environment or her aspirations of the future.

\section{Mental health}

Ms A had a history of aggressive outbursts dating back to childhood. During her hospital admission at the age of 47 , these were felt to be in response to auditory and visual hallucinations. These symptoms were treated with antipsychotics and it 
was considered that they were well controlled at the time of assessment. Ongoing aggressive outbursts were considered to be expressions of frustration arising from her limited coping abilities as a consequence of her intellectual disability rather than a symptom of mental illness.

\section{Understanding of surgical/medical diagnosis and proposed treatment}

A small team of professionals undertook to discuss with Ms A her diagnosis of breast carcinoma and the recommended treatment. It comprised the speech and language therapist, the community learning disability nurse and the specialist breast care nurse. Overall, Ms A was assessed as lacking the ability to understand, retain and weigh up information about her diagnosis, although she understood that it was serious and she was concerned about it. She also lacked understanding of the short- and long-term consequences of the proposed treatments (which included surgery, chemotherapy and radiotherapy) and of choosing to decline any of them.

\section{Previous capacity to make complex decisions}

Ms A had lived with her parents until the age of 36 and had had little opportunity to make complex decisions with regard to treatment. She was able to make choices with regard to aspects of day-to-day living such as what to eat and leisure activities. However, in more complex situations, such as her move to residential care, it was considered that she had been unable to make a clear or consistent decision. Furthermore, it was noted that impairments in her comprehension and communication presented challenges in assessing her opinion and wishes.

\section{Previous experience of medical investigations and treatment}

Ms A had in the past cooperated with attending general practitioner and hospital appointments, allowed blood tests and other investigations, and adhered to treatment, including medication, with appropriate support.

\section{The test of capacity to consent to treatment}

To help determine whether a person lacks capacity to make particular decisions, such as consent to treatment, the Mental Capacity Act sets out a twostage test of capacity.

\section{Stage 1}

Stage 1 requires proof that the person has an impairment of the mind or brain, or some sort of disturbance, that affects the way their mind or brain works. Section 2(2) of the Act states that the impairment or disturbance need not be permanent and a person can lack capacity to make a decision at the time it needs to be made even if: (i) the loss of capacity is partial; (ii) the loss of capacity is temporary, or (iii) their capacity changes over time. Examples of such conditions include dementia, significant intellectual disability, conditions associated with some forms of mental illness, the long-term effects of brain damage, physical or medical conditions that cause confusion, drowsiness or loss of consciousness, delirium, concussion following a head injury and the symptoms of alcohol or drug use. If the person does not have such an impairment or disturbance of the mind or brain, they will not lack capacity under the Act.

Ms A had mild intellectual disability, an enduring condition that was unlikely to improve. Her cognitive, adaptive and communication skills were significantly impaired and she was therefore considered to meet stage 1 of the capacity test.

\section{Stage 2}

In stage 2, the Act says that for a person to lack capacity to make a decision their impairment or disturbance must affect their ability to make the

BOX 3 Checklist of points to consider in helping someone make a specific decision for themselves

1 Providing relevant information

Does the person have all the relevant information they need to make a particular decision?

If they have a choice, have they been given information on all the alternatives?

2 Communicating in an appropriate way

Could information be explained or presented in a way that is easier for the person to understand (for example, by using simple language or visual aids)?

Have different methods of communication been explored if required, including non-verbal communication?

Could anyone else help with communication (for example, a family member, support worker, interpreter, speech and language therapist or advocate)?

3 Making the person feel at ease Are there particular times of the day when the person's understanding is better?

Are there particular locations where they may feel more at ease?

Could the decision be put off to see whether the person can make the decision at a later time when circumstances are right for them?

4 Supporting the person Can anyone else help or support the person to make choices or express a view?

(Department for Constitutional Affairs 2007) 
specific decision when they need to. However, first the person must be given all practical and appropriate support to help them make the decision for themselves (Box 3). Stage 2 can only apply if all practicable and appropriate support to help the person make the decision has failed. A communication strategy to help Ms A was developed by the speech and language therapist and team psychologist to facilitate communication. This involved presenting information about breast cancer and the proposed treatment options both verbally in plain English and visually using sketches, pictures and photographs. In stage 2 of the test of capacity, Ms A:

- was unable to understand the information provided to her about her diagnosis and proposed treatment and its implications, even with specific adaptations to facilitate her comprehension;

- was therefore unable to retain the relevant information about her diagnosis and proposed treatment and its implications;

- was therefore unable to use or weigh up the information provided to her about her diagnosis, proposed treatment, its implications, and the benefits and risks of making a decision;

- also had significant limitations in her verbal communication skills and, despite facilitation by the speech and language therapist, was unable to understand or communicate her decision.

It was thus established that Ms A met the criteria of both stages of the test of capacity and it became necessary to come to a decision in her best interests.

\section{Best interests}

The 'best interests' principle is referred to in Section 1(5) of the Mental Capacity Act: 'an Act done, or decision made, under this Act for or on behalf of a person who lacks capacity must be done, or made, in his best interests'. The term 'best interests' is not defined in the Act, because of the many different types of decisions covered by the Act. It applies to people who lack capacity to make individual decisions for themselves and covers all aspects of their financial and personal welfare and healthcare decisions and actions.

There are two circumstances when the best interests principle as described in the Act does not apply: (i) when someone has previously made an advance decision to refuse medical treatment while they had the capacity to do so; ${ }^{\ddagger}$ and (ii) involvement in research of someone who lacks capacity to consent, although even then the interests of the participant outweigh any potential benefit to others (Dobson 2008: p. 20).

\section{Serious medical treatment}

For the purposes of the Mental Capacity Act, serious medical treatment is defined as giving new treatment, stopping treatment that has already started or withholding treatment that could be offered: (i) where a single treatment is being proposed and there is a fine balance between the benefits to the patient and the burdens and risks it is likely to entail for them; (ii) where there is a choice of treatments, a decision as to which one to use is finely balanced; or (iii) where the proposed treatment is likely to involve serious consequences for the patient (Secretary of State 2006).

In Ms A's case, the proposed treatment would constitute serious medical treatment that a National Health Service (NHS) body (the surgical team) was proposing to provide in circumstances in which there was a fine balance between the benefits to Ms A and the risks and complications of the surgical procedure and subsequent radiological and chemotherapeutic treatments.

\section{Independent mental capacity advocate (IMCA)}

The Mental Capacity Act 2005 introduced the statutory role of the IMCA to support people who lack capacity to make certain decisions. Regulations for England and Wales impose a duty on the NHS body to instruct an 'independent mental capacity advocate' (IMCA) to be involved in the best interests decision-making process where serious medical treatment is proposed regarding serious medical treatment or change of accommodation of a person who has no close family or friends to represent their views and who has been deemed by the 'decision maker' not to have capacity to make that decision in accordance with the Act. After a full assessment of the situation on behalf of the individual (Box 4), the IMCA submits a report

BOX 4 The functions of an independent mental capacity advocate regarding serious medical treatment

- Representing and supporting a person who lacks capacity

- Obtaining and evaluating information, including accessing client records relevant to the decision

- Ascertaining the person's wishes and feelings as far as possible

- Ascertaining whether alternative courses of action have been considered

- Obtaining a further medical opinion if necessary

- Submitting a report to the decision maker outlining their findings 
to the decision maker outlining their findings. This is used when weighing up the information in accordance with the best interests checklist (Box 5) before a final decision is made.

Ms A had close family and friends involved and hence an IMCA was not required. There had been no occasions in the past when her capacity to consent to medical or surgical treatment had been required and, given her communication difficulties, her wishes and beliefs could not be ascertained and taken into account. Therefore the multidisciplinary team, Ms A's family and the surgical team (the decision maker) and a patient advocate were involved in the best interests decision process. The condition, prognosis and treatment options were weighed up and it was considered that the proposed breast surgery followed by chemotherapy would be in Ms A's best interests. The best interests decision regarding radiotherapy could not be made at that time as the appropriateness of this treatment could not be assessed until after surgery and tissue analysis.

\section{Confidentiality}

Ethical codes and laws require professionals to keep personal information confidential. People involved in assessing capacity and making best interests decisions need to share information about an individual's circumstances. Hence, as a general rule, professionals must ask their patients for permission to reveal information to somebody else - even close relatives - and

BOX 5 Checklist of points to consider in coming to a decision in someone's 'best interests'

1 Encourage participation

2 Identify all relevant circumstances

3 Find out the person's views

4 Avoid discrimination

5 Assess whether the person might regain capacity

6 If the decision concerns life-sustaining treatment

7 Consult others

8 Independent mental capacity advocate (IMCA)

9 Avoid restricting the person's rights
Do whatever is possible to permit and encourage the person to take part, or to improve their ability to take part, in making the decision

Try to identify all the things that the person who lacks capacity would take into account if they were making the decision or acting for themselves

Try to establish:

past and present wishes and feelings - these may have been expressed verbally, in writing or through behaviour or habits

any beliefs or values (e.g. religious, cultural, moral or political) that would be likely to influence the decision in question

any other factors the person would be likely to consider if they were making the decision or acting for themselves

Do not make assumptions about someone's best interests simply on the basis of their age, appearance, condition or behaviour

Consider whether the person is likely to regain capacity (e.g. after receiving medical treatment). If so, can the decision wait until then?

Do not be motivated by a desire to bring about the person's death: do not make assumptions about the person's quality of life

If it is practical and appropriate to do so, consult other people for their views about the person's best interests and to see whether they have any information about the person's wishes and feelings, beliefs and values

In particular, try to consult:

anyone previously named by the person as someone to be consulted on either the decision in question or a similar issue

anyone engaged in caring for the person

close relatives, friends or others who take an interest in the person's welfare

any attorney appointed under a Lasting (formerly Enduring) Power of Attorney made by the person

any deputy appointed by the Court of Protection to make decisions for the person

(when consulting, remember that someone who lacks the capacity to make a decision or act for themselves still has a right to keep their affairs private - so it would not be right to share every piece of information with everyone)

For serious medical treatment or decisions on where the person should live, an IMCA must be consulted if there is no one who fits in into any of the categories listed in the consultation section above

Find out whether there are other options that may be less restrictive of the person's rights

(Department for Constitutional Affairs 2007) 
MCQ answers

$\begin{array}{lllll}1 \mathrm{c} & 2 \mathrm{e} & 3 \mathrm{~d} & 4 \mathrm{a} & 5 \mathrm{a}\end{array}$ give a full explanation of why it is necessary to reveal it. Every effort should be made to gain this consent. In many cases the person will be able to give permission but the professional might still be allowed to provide information that will help make an accurate assessment of the person's capacity to make the specific decision. Sometimes, information may be disclosed without the consent of the person whom it concerns, for example to protect the person or prevent harm to other people ( W v. Egdell and others 1990; S v. Plymouth City Council and C 2002).

It is good practice for professionals to record the process of assessment, the findings, discussions and decisions accurately and comprehensively in their respective professional records.

\section{Subsequent care of Ms A}

A detailed management plan to prepare Ms A for surgery and manage her mental health problems before and after surgery was prepared by the learning disability team. Information about the hospital, the staff, the surgery and after-care was presented in plain English using verbal and written materials, photographs and pictures of the surgical team and hospital. Visits were arranged to the hospital prior to surgery and were combined with activities that Ms A enjoyed, such as going for a drink or meal at the hospital cafeteria. Ms A underwent surgery successfully. Nursing staff from the learning disability services supported her during her admission to the surgical unit. She was subsequently discharged back to the learning disability unit and attended follow-up surgical out-patient appointments. Her wound healed well and she recovered well from surgery. Radiotherapy was recommended and the multidisciplinary team met once again to consider whether this was in her best interests. It was felt that it was. She responded well to the treatment and was discharged from the learning disability unit to a residential care home, where she remained well and engaged in a regular activity programme. Unfortunately, she subsequently developed metastases and died 3 years later.

\section{Other issues}

\section{Declining a capacity assessment}

There may be circumstances in which a person whose capacity is in doubt refuses to undergo an assessment of mental capacity. Nobody can be forced to undergo such an assessment (Department for Constitutional Affairs 2007). It is important to explain to the person refusing the assessment why it is needed and what the consequences of refusal are. If the person lacks capacity to agree to or to refuse an assessment, it can normally go ahead provided that the person does not object and it is in their best interests (Department for Constitutional Affairs 2007). If there are serious concerns about a person's mental health and a capacity assessment is felt to be appropriate but they are refusing this, it may be appropriate to assess them under the Mental Health Act 1983. However, simply refusing an assessment of capacity is not sufficient grounds for assessment under the Mental Health Act.

\section{Challenging a finding of lack of capacity}

There may be occasions when someone (including, but not only, the patient) wishes to challenge the outcome of a capacity assessment. The doctor who carried out the assessment may be asked to give reasons why they believe the person lacks capacity to make a decision and provide objective evidence to support that belief. In such cases the doctor must show that they have applied the principles of the Mental Capacity Act. A second opinion from an independent professional may be sought. If a disagreement cannot be resolved, the person challenging the assessment may refer the matter to an appropriate Court, depending on the gravity of the capacity decision in question. The Court of Protection in some cases can rule on whether a person has capacity to make the decision covered by the assessment.

\section{Conclusions}

The Mental Capacity Act 2005 provides the legal framework for use in everyday clinical practice in England and Wales with adults who lack the capacity to consent to treatment. Where the incapacity is permanent or likely to be long-standing, the Act's Code of Practice provides guidance on lawfully carrying out any procedure which is in the 'best interests' of the patient (Department for Constitutional Affairs 2007). Where there is doubt as to the patient's capacity or best interests, a referral needs to be made under the Mental Capacity Act to the Court of Protection. This body now deals with serious decisions affecting personal welfare matters, including healthcare, which were previously dealt with by the High Court. Other circumstances when a referral should be made to the Court of Protection regarding an adult lacking capacity to consent include non-therapeutic sterilisation, cases involving organ, bone marrow or peripheral blood stem cell donation and withdrawal of artificial nutrition and hydration from patients in a persistent vegetative state. 


\section{Acknowledgements}

Our thanks to: Jenny Follows for her secretarial support and typing of the manuscript; and to an anonymous reviewer for assistance in editing the text. We also thank the family of Ms A, for permission to publish this article.

\section{References}

Ammons RB, Ammons CH (1962) The Quick Test (OT): Provisional Manual. Psychological Reports

Department for Constitutional Affairs (2007) Mental Capacity Act 2005: Code of Practice. TSO (The Stationery Office) (http://www.dca.gov.uk/ legal-policy/mental-capacity/mca-cp.pdf)

Department of Health (2008) Mental Capacity Act 2005: Deprivation of Liberty Safeguards. Code of Practice to Supplement the Main Mental Capacity Act 2005 Code of Practice. TSO (The Stationery Office) (http://www.dh.gov.uk/en/Publicationsandstatistics/Publications/ PublicationsPolicyAndGuidance/DH_085476).

Department of Health (2009) Reference Guide to Consent for Examination or Treatment (2nd edn). TSO (The Stationery Office) (http://www.dh.
gov.uk/en/Publicationsandstatistics/Publications/PublicationsPolicyAnd Guidance/DH_103643).

Dobson C (2008) Conducting Research with People Not Having the Capacity to Consent to Their Participation: A Practical Guide for Researchers. British Psychological Society.

Raven J, Raven JC, Court JH (2003) Manual for Raven's Progressive Matrices and Vocabulary Scales. Section 1: General Overview. Harcourt Assessment.

Reitan RM (1992) Trail Making Test: Manual for Administration and Scoring. Reitan Neuropsychology Laboratory.

Secretary of State (2006) Statutory Instrument 2006 No. 1832: The Mental Capacity Act 2005 (Independent Mental Capacity Advocates) (General) Regulations 2006. TSO (The Stationery Office) (http://www.opsi.gov.uk/ acts/acts2005/ukpga_20050009_en_2\#pt1-pb2-11g5).

Wechsler D (1997a) Wechsler Memory Scale (3rd edn). The Psychological Corporation.

Wechsler D (1997b) Wechsler Adult Intelligence Scale (3rd edn). The Psychological Corporation.

S v Plymouth City Council and C (2002) EWCA Civ 388 at 49.

Wv Egdell and others (1990) 1 All ER 835 at 848.
MCOs

Select the single best option for each question stem

1 The principles underpinning the Mental Capacity Act 2005 exclude the following:

a people are presumed to have capacity

b all practicable steps must be taken to support someone in decision-making

c a person is to be treated as lacking capacity if they repeatedly keep making unwise decisions

$\mathrm{d}$ an action taken on behalf of a person must be in their best interests

e regard must be had as to whether an act or decision is the least restrictive of a person's rights and freedoms.

2 Conditions that could affect an individual's capacity to consent are unlikely to include:

a dementia of the Alzheimer's type

b Cornelia de Lange syndrome

c alcohol withdrawal delirium

d concussion following a head injury

e Marfan's syndrome.

\section{As regards capacity assessment:}

a a person with severe aggressive behaviour, autism and intellectual disability can be assumed to lack capacity

b supporting a person who seems to lack capacity to make a decision for themselves by facilitating their understanding just delays treatment

c the capacity assessment is invalid if more than one member of the multidisciplinary team disagrees with its conclusions

d a person's capacity must be assessed specifically in terms of their capacity to make a particular decision at the time it needs to be made

e it is better to agree with a carer with strong opinions regarding capacity of the person concerned than to discuss the matter should it result in a disagreement.

4 The functions of the independent mental capacity advocate do not include:

a colluding with the patient's carers if they appear to have the right views, against the patient b obtaining and evaluating information including accessing client records relevant to the decision

c ascertaining the person's wishes and feelings as far as possible

d obtaining a further medical opinion if necessary

e ascertaining whether alternative courses of action have been considered.

5 The best interests decision maker:

a may consult the best friend of the person who lacks capacity, even if that person is reported by a family member to be best avoided

b can overlook advance decisions made by the patient

c is accountable for the consequences of the best interest decision

$d$ has to be appointed by the Court of Protection

e when consulting, should share all information with everyone involved in the patient's care, for completeness, without regard to the patient's privacy. 